\title{
A Summary of Researches on Flexible Management of Excitation Scientific and Technical Personnel Innovation
}

\author{
Liqin Li \\ Xi'an International University, Xi'an, Shaanxi, 710077 \\ liliqin@xaiu.edu.cn;
}

Keywords: Scientific and Technical Personnel, Flexible Management, Innovation, Encouragement

\begin{abstract}
Scientific and technical personnel as the core staff of the organization, for the scientific and technological personnel is particularly important incentive. This paper summarizes the research results of the research on the flexible management of scientific and technical personnel both at home and abroad, and makes a literature review.
\end{abstract}

\section{Introduction}

Motivating employees is an important part of organizational management, and effective incentives can inspire employees $70 \%-80 \%$ of their job potential; if there is no incentive, employees may only play their $20 \%-30 \%$ potential. Scientific and technical personnel as the core staff of the organization, for the scientific and technological personnel is particularly important incentive. This paper summarizes the research results of the research on the flexible management of scientific and technical personnel at home and abroad, which is summarized as follows.

\section{The Status Quo of Foreign Research}

In Terms of Performance Appraisal: France for the evaluation of scientific research personnel, taking a combination of macro and micro indicators, with resources, strategy (research direction, planning) and competitiveness (industrial technology competitiveness) to evaluate scientific research management, Assessing the level of research with inputs, outputs, relationships (research collaboration, staff mobility) and benefits (impact on society). Japan proposed the basic research and applied research classification evaluation, advocate open research evaluation system that should be the evaluation criteria, evaluation of the main body, the evaluation results and their use are given open. Domestic peer review method of the mainstream status and the law is used in the evaluation of scientific research, scientific research and identification and evaluation, degree and title assessment, scientific research performance evaluation [1].

In The Field of Talent Incentives: Alcine and Demsetz in 1972, "American Economic Review" published papers "production, information costs and economic organization" to become a team production theory of the classic literature, LaZear. Baker and Hamilton for the agent People's performance-based compensation program to carry out the results of the study, the team incentives put forward new insights, thus contributing to the development of team production theory. Team remuneration against traditional personal pay system, advocate pay should reflect the team's performance. Thus, the team pay should first reflect the impact of team performance on individual pay, as this leads the individual effort towards the team's goals and direction (Heneman and VonHippel, 1995). Landis (1971) concluded that achievement incentives, monetary incentives, nonmonian incentives, job challenges, work relationships, and work are themselves the six most important incentives for R \& D personnel. Starketal (1996) developed a Team Reward Attitude TRA evaluation system to measure the relevance of personal attitudes to team output [2]. 
In Terms of Flexible Management: If the "Taylor system", which was born in the United States more than 100 years ago (1897), opened the door to the "modern management" of the organization, and "scientific management" replaced the "experience management" Management has gone through the first revolution, then, after the 20th century, the behavior of science, system theory, decision-making theory, total quality management, business process reorganization and other transitional evolution, in the human into the 21st century, Organizational management of the second revolution - flexible management. The study of flexible management first originated in the 1930s economist Hart (Hari, 1937) and others to study the impact of the economic cycle of shock on the organization; then, Hopf in the "Management Proceedings" from the excellent the problem of organizational flexibility is expounded. He argues that the state of optimism is a comprehensive balance between all factors, and that in order to maintain that balance is the development of the overall goals of the organization, and sometimes may be part of the interests of the sacrifice. The realization of dynamic optimization state requires that the organization has high flexibility, that is, flexibility, so that the organizational performance to achieve dynamic optimal [3]. Peter Drucker (2006) advocates to create the best performance of the organization in "the management of the next society" and should motivate employees in a good way to motivate employees to stimulate their sense of responsibility, creativity and vitality The His main ideas for the incentive mechanism are: the incentive to the core of the measures; reasonable and fair promotion system for the incentive basis; timely and impartial incentives for the incentive catalyst [4].

\section{The Status of Domestic Research}

Scientific and Technological Personnel Incentive Research: Pan Jinshan, Liu Jike (2001) and so that from the internal terms, by strengthening the incentive mechanism, the implementation of a variety of interests to achieve the way, pay attention to good scientific and technological innovation and cultural atmosphere, so as to mobilize the inherent scientific and technological personnel From the outside, through the strengthening of the relevant legislation, implementation, the establishment of effective R \& D investment and distribution forms, as well as the effective combination of existing scientific and technological personnel, which for technological innovation of technological talent to provide a fair, open and competitive environment [5]. Zhang Jun (2002), by drawing on the traditional comprehensive incentive model, and on the basis of the comprehensive incentive model, the incentive factors of the scientific and technological personnel are determined as: ability factor, property factor, reward factor, stress factor and power factor. Lu Qinyong, Ba Lianliang and other claims, the use of target incentives, organizational incentives, "gill fish", emotional incentives, prospects and other incentives to stimulate scientific and technological personnel continue to innovate [6]. On the basis of a comprehensive analysis of the existing problems in the current research management incentive work, Wang Chuhong and Chen Miaolong (2014) do a good job in stimulating the work plan, making the evaluation index system, grasping the incentive scale, doing the support of property rights work and improving the information feedback mechanism. [7]. (2014) uses the analytic hierarchy process as a tool to proceed from the five indicators of culture and goal, people-oriented, scientific assessment, quality orientation and team motivation. Through the establishment of evaluation index, the quantitative index is used to synthesize the incentive mechanism of scientific research innovation Evaluation and quantitative calculation, to determine the optimal incentive mechanism [8]. Wanjuanxiu (2015) that the public welfare research institutes personnel incentive mechanism to establish the material and spiritual balance, the implementation of a comprehensive salary incentive mechanism, in the financial support of the co-ordination, to the first line of young researchers tilt to encourage innovation. Attention to the incentives of researchers, incentives and objectives will be combined to establish a variety of public welfare in line with the incentive mechanism, but also for public welfare research institutes to provide further development of the power [9]. Guo Yingyuan (2015) pointed out in his article that the participation of scientific and technological personnel in the transformation of scientific and technological achievements is the key to the incentive mechanism of technological innovation, and put forward the theoretical basis of "knowledge spectrum" as the incentive of scientific and technical personnel distribution. 
And from the scientific and technological personnel to participate in scientific and technological achievements into the income distribution incentive mechanism of legal protection, restraint mechanisms, quantitative rules, incentives and other aspects of the specific elaboration [10].

Flexible Management Research: Zhang Meng (2004) system to explain the scientific and technological personnel have the autonomy, innovation, high mobility, labor complexity and other characteristics, she believes that flexible management should be with the whole process of strict management The realization of flexible management must have a high-quality workforce, at the same time to create a positive corporate culture, training staff team spirit and self-realization of high-level needs, only on this basis, flexible management can really play its some effect [11]. Tang Huashan (2006) that flexible management can inspire people's creativity. Explicit knowledge is well known, and tacit knowledge exists only in the minds of employees, it is difficult to grasp and control. Only through the flexible management can exist in the minds of the staff in the knowledge development, guide out, through a certain incentive mechanism, so that employees put their ideas and ideas put forward in the organization to achieve knowledge sharing, better and faster to promote the organization Innovation, and enhance organizational competitiveness [3]. Zhao Lei, Cui Weifang (2015) and others proposed the use of contract management to achieve flexible management. Contract management shows greater flexibility, reflects the management of democracy and fairness, but also reduce the interests of both sides and the purpose of the differences brought about by the opposition, more easily accepted by the managers. Contract management as an important way in flexible management, it can effectively compensate for the existing scientific research management system model defects [12].

\section{The Literature Review}

Throughout the relevant research at home and abroad, to encourage scientific and technological personnel innovation mainly presents the following characteristics:

First, in the research of talent incentive, domestic and foreign scholars from the initial material incentives gradually transformed into the spirit of human management incentives, team incentives;

Second, the performance management of scientific and technological personnel, foreign pay more attention to multi-subject research evaluation system, and domestic peer evaluation method for the mainstream evaluation method, limited the scope of the evaluation of scientific and technological personnel;

Third, in the study of flexible management, both at home and abroad have emerged from the rigid management to flexible management of the trend. And in foreign research has become more mature, the domestic flexible management system research is still in the initial stage.

It can be seen that there are few researches on stimulating scientific and technological personnel innovation in existing achievements, and the use of flexible management system to encourage scientific and technological personnel to achieve less innovative literature.

\section{Acknowledgements}

Fund Project: Shaanxi Province 2017 Science and Technology Department of soft science research project; project name: research on incentive technology personnel innovation and flexible management; Question Number: 2017KRM094. Shaanxi Province, the subject of education and scientific planning, Shaanxi private colleges and universities teacher evaluation research based on the application of personnel training, SGH17H419

\section{References}

[1] Feng Shaohong. Research on the Incentive of Staff in Public Welfare Scientific Research Institutions - Based on the Thinking of Working Values[M]. Science Press, 2012

[2] Zhu Fei. Performance incentive and salary incentive[M]. Enterprise Management Press, 2013 
[3] Tang Huashan. Soft rope bundle hardwood flexible management of the power [M]. Guangzhou: Guangdong Economic Publishing House .2006

[4] Peter Drucker. The management of the next society[M]. Beijing: Mechanical Work Publishing House .2006

[5] Pan Jinshan, Liu Jike, Huang Ma Li. Chinese scientific and technological personnel technical innovation inside and outside the support environment $[\mathrm{J}]$. China Science and Technology Forum, 2001 (2): 58-61

[6] Zhang Jun, Gong Jianli. Research on the Incentive Factors of Scientific and Technical Personnel[J]. Science of Science and Management of Science and Technology, 2002 (8): 82-85

(1): 150-155 (in Chinese) [J] .Journal of Guangdong University of Science and Technology (Social Science Edition)

Journal of Shandong Agricultural Engineering Institute, 2014 (2): 49-50 + 53.Study on the Evaluation of Incentive Mechanism of Scientific Research Innovation in Colleges and Universities Based on Analytic Hierarchy Process [J]. Journal of Shandong Agricultural Engineering Institute, 2014 (2): 49-50 + 53

[9]: WAN Jia-xiu, ZHENG Miao-juan, YANG Dong-xu, WU Gang.Study on the Current Situation and Countermeasures of Personnel Incentive Mechanism in Public Welfare Scientific Research Institutes [J]. Today's Technology, 2015 (9): 47-48 +55

[J] .Journal of Science and Technology Management, 2015 (7): 146-154 (in Chinese with English abstract). [J]. Science and Science and Technology Management, 2015 (7): 146-154 [J].

[11] ZHANG Meng-shi, WANG Wen-kui.Study on Flexible Management Based on Scientific and Technical Personnel Characteristics [J]. Future and Development, 2004 (5): 15-17

[12] Zhao Lei, Cui Weifang, Wang Zhigang, Wang Junwei. Flexible management of scientific research in colleges and universities[J]. Chinese University Science and Technology, 2015 (5): 24-25.

[13] Song Hui, Lv Huqiao.Study on the Construction of Innovation System of Local Scientific Research Institutions in Deepening the Reform of Science and Technology System [J] .Journal of Science and Technology Management, 2013 (15): 1-4

[14] Wong W, Radcliffe D F. The tacit nature of design knowledge[J]. Technology Analysis \& Strategic Management, 2000, 12 (4): 493-512

[15] Tienari, J. \& R. Tainioy. The myth of flexibility in organization change [J]. Scandinavian of Journal of Management. 1999 (15): 351-384

[16] Hou Guangming, Li Cunjin. Modern management incentive and restraint mechanism[M]. Higher Education Press, 2002

[17] F Phillips, SD Tuladhar. Measuring Organizational Flexibility: An Exploration and General Model[J]. Technological Forecasting \& Social Change, 2000, 64 (1): 23-38. 